\title{
COMO SE CONSTRÓI UM EDUCADOR FREIRIANO E PESQUISADOR RIGOROSO?
}

Dagmar M. L. Zibas ${ }^{1}$

I Doutora em Educação pela Universidade de São Paulo (USP), Brasil; pzibas@fcc.org.br

Cabral Neto, A. (2021). Trajetória e escritos de um educador: Reflexões sobre política e gestão educacional. CRV.

A inspiradora abordagem desse livro traz, como núcleo, o memorial do autor (apresentado como parte das exigências do concurso para professor titular da Universidade Federal do Rio Grande do Norte - UFRN) e 13 artigos publicados entre as décadas de 1990 e 2000. São textos selecionados de forma a colocar em relevo os principais temas pesquisados pelo Prof. Cabral Neto em sua longa e muito produtiva vida acadêmica, ou seja, democracia, Estado, planejamento educacional, políticas educacionais e gestão escolar.

Um livro com tal enfoque retrospectivo pode, talvez, suscitar algumas questões, tais como: essa publicação nos dará pistas relevantes para a compreensão dos avanços e tropeços da educação brasileira ao longo das últimas décadas? Trará subsídios para o enfrentamento dos gravíssimos problemas que o atual retrocesso das políticas educacionais nos coloca?

Dois exemplos das virtudes didáticas e provocadoras do conjunto de textos podem ser citados. Por um lado, constatamos um original entrelaçamento entre a trajetória pessoal e profissional do autor e a própria história do nosso sistema público de ensino. Ou seja, o processo de formação do educador Antônio Cabral Neto é muito ilustrativo tanto dos avanços quanto das mazelas da educação pública brasileira. Por outro lado, os artigos agora republicados desvendam, de forma muito clara, os acirrados debates técnicos e os históricos embates político-ideológicos que têm pautado a gestão do sistema de educação e a implementação das políticas educacionais no Brasil. Tal perspectiva histórica é ferramenta essencial para se pensarem estratégias de resistência ao atual desmanche das sofridas conquistas alcançadas nas últimas décadas no âmbito da escola pública.

De fato, a descrição do caminho educacional do autor nos confronta com um Brasil onde, nas décadas de 1950 e 1960, as populações rurais, principalmente (mas não só) no Nordeste, estavam alijadas de qualquer oportunidade de educação formal, constituindo grandes massas de analfabetos vivendo em condições feudais de trabalho. País onde os raros e prestigiados ginásios públicos estavam localizados apenas em capitais ou grandes centros e cujas vagas eram destinadas aos filhos de famílias ricas ou preenchidas por adolescentes indicados por caciques políticos. Brasil onde, nos anos 1970, promissores jovens nordestinos, graduados em Pedagogia, deveriam, necessariamente, deslocar-se para o Sudeste para continuar seus estudos de mestrado e doutorado. 
Ainda é necessário destacar que a história profissional do autor se confunde com o próprio desenvolvimento da excelência acadêmica da UFRN. Com mestrado e doutorado em universidades do Sudeste, Prof. Cabral Neto tornou-se um dos expoentes da renomada Pós-graduação em Educação da UFRN, que tem formado, desde a década de 1980, quadros importantes de docentes-pesquisadores, com notável contribuição para a produção científica na área.

No entanto, é preciso lembrar que o garrote político-ideológico, colocado pela ditadura militar sobre as universidades públicas, inevitavelmente retardou o desenvolvimento de uma leitura crítica de seu campo de estudo por parte de graduados e pós-graduados em Educação. A trajetória do Prof. Cabral Neto também foi afetada por essa orientação universitária tecnicista, acrítica, economicista e pretensamente apolítica, predominante no Brasil nos anos 1970. O encontro com a obra de Paulo Freire e a participação em diversos grupos de estudo, debates e pesquisas, que já no início da década de 1980 construíam, inclusive na UFRN, uma bem-fundamentada linha de pensamento histórico-crítico, provocaram um deslocamento radical da postura profissional e política do autor. Desenvolve-se, então, com a contribuição do curso de doutorado na Universidade de São Paulo (USP), o árduo trabalho de formação do educador freiriano e do pesquisador crítico e rigoroso, que se expressa plenamente nos 13 artigos que compõem esse livro.

Impossível aqui comentar toda a ampla gama de diferentes tópicos analisados e os férteis subsídios que a coletânea fornece para a discussão dos atuais problemas políticos e educacionais que enfrentamos. No entanto, essas qualidades de todos os textos podem ser exemplificadas ao focarmos três deles, especificamente aqueles de maior abrangência analítica, pois tratam dos processos da constituição do Estado democrático e de instrumentos concebidos para seu funcionamento.

Não é por acaso que o primeiro trabalho selecionado pelo autor discuta o tema da democracia, sob o título "Democracia: velhas e novas controvérsias". Esse artigo representa um avanço crítico importante, ao rejeitar a abstração liberal e postular um conceito de democracia que abranja, no processo de sua construção, os atores sociais que, por condições precárias de vida, estão alijados das benesses do sistema democrático tradicional. Ou seja, uma democracia que amplie seus limites para incorporar a dimensão social, econômica, política e cultural da sociedade. Sem dúvida, neste momento de arregimentação social para a defesa do Estado democrático e de direito, as considerações de Cabral Neto nos desafiam a compreender que essa tarefa vai além da garantia de realização das próximas eleições, exigindo também a elaboração de projetos de real inclusão dos interesses das classes populares no processo de reconstrução de nossa fragilizada democracia.

Dentro da mesma temática, o texto "Notas sobre o Estado do Bem-Estar Social" desenvolve uma esclarecedora revisão dos escritos de Claus Offe e de alguns especialistas brasileiros. O autor conclui que a profunda crise econômica e social, que colocou em xeque o Welfare State europeu, atingiu fortemente o âmbito do trabalho, e não o do capital. Ao voltar sua análise para o Brasil, Cabral Neto destaca que sempre foi mais adequado classificar nosso desenvolvimento social como muito limitado e seletivo quanto aos interesses dos trabalhadores, uma vez que, historicamente, prevalecem políticas de favorecimento da reprodução do capital. Configura-se, então, entre nós, um estado de mal-estar social para a maior parte da população.

Note-se que esse artigo foi originalmente publicado em 1995. De lá para cá, houve um período de reconhecido avanço de políticas que propiciaram alguma distribuição de renda, políticas que anunciavam um novo patamar de enfrentamento da desigualdade social. O desmantelamento, a partir de 2016, do nosso frágil arcabouço de proteção social instala retrocessos que não podiam ser imaginados nos meados da década de 1990. No entanto, a perspectiva histórica delineada parece levantar o seguinte desafio: se foi possível avançar socialmente (em especial na primeira década do século XXI), a partir de um precário patamar de desenvolvimento social e no bojo de duros confrontos políticos, quais caminhos trilhar para recuperar a possibilidade da construção de um Estado de Bem-Estar social entre nós? 
O artigo "Planejamento como instrumento de intervenção - resgatando elementos para debate", publicado em 1997, traz uma revisão histórica do conceito de planejamento e da paulatina adoção dessa técnica de administração da economia por parte de sucessivos governos desde o início do século XX, bem como sua consolidação durante a ditadura inaugurada em 1964. Há uma bem fundamentada crítica do autor ao planejamento centralizado dos governos militares, que, além de esvaziar o poder dos entes federativos, gerou, no Nordeste, apenas ligeira e superficial modernização da produção, sem qualquer benefício para a imensa maioria da população.

No entanto, o texto avança para a análise do planejamento participativo, que, com o fim do regime militar, teve uma vigência de âmbito nacional. Na verdade, a euforia cívica pela debacle do regime ditatorial gerou a confiança de que a sociedade civil seria competente para participar da elaboração de projetos locais e do orçamento público. Todavia, Cabral Neto constata que a tendência predominante foi de participação apenas formal, prevalecendo estratégias de manipulação dos atores sociais. A conclusão é de que somente uma sociedade minimamente organizada estaria apta a tal tarefa, o que não era o caso do país apenas recentemente resgatado da letargia dos anos de chumbo.

A questão que esse artigo nos coloca parece ser a seguinte: se as técnicas de planejamento, tanto em sua forma centralizada quanto em uma concepção participativa, não geraram avanços significativos para a precária condição social de nossa população, o que podemos colher de um momento histórico de grande fragilização das instituições e da sociedade civil e total rendição $\mathrm{da}$ economia brasileira às exigências vorazes e flutuantes do mercado, sem que qualquer meta de desenvolvimento ou qualquer planejamento estejam minimamente traçados? Sem dúvida, tal cenário delineia uma tarefa hercúlea a ser enfrentada pela cidadania no muito aguardado período de reconstrução nacional.

Os textos seguintes discutem mais especificamente tópicos de política educacional e gestão da educação. Esses campos constituem o foco principal das pesquisas e da atuação profissional do Prof. Cabral Neto. São, pois, conteúdos que contribuem de forma fecunda para a compreensão dos debates que permearam os avanços e recuos da área da Educação nas últimas décadas. Além disso, as cuidadosas análises desenvolvidas podem ajudar no esboço de processos de recuperação do sistema público de ensino e do imprescindível redirecionamento democrático das políticas para a educação.

Cabe ainda destacar quatro significativos textos introdutórios à coletânea.

O prefácio, assinado pelas professoras Alda Maria A. R. Castro e Magna França, é uma substanciosa apresentação que dialoga com o autor por meio dos temas por ele desenvolvidos.

Além dessa profícua introdução, três renomados intelectuais, Dalila Andrade Oliveira, Luiz Fernandez Dourado e Oswaldo H. Yamamoto, trazem seus testemunhos sobre a fértil interlocução que mantêm há décadas com o Prof. Cabral Neto, destacando a excelência dos textos selecionados e a grande relevância da atuação profissional do autor para o desenvolvimento da pesquisa em Educação e para a formação rigorosa de docentes e pesquisadores.

Como se vê, trata-se de livro referendado por uma trajetória pessoal e profissional de mérito amplamente reconhecido; obra cuja leitura abrirá, com certeza, novas e fecundas perspectivas de análise para profissionais e estudantes da área.

\section{Referências}

Cabral Neto, A. (2021). Trajetória e escritos de um educador: Reflexões sobre política e gestão educacional. CRV. 


\section{Como citar esta resenha}

Zibas, D. M. L. (2021). Como se constrói um educador freiriano e pesquisador rigoroso? [Resenha do livro Trajetória e escritos de um educador: Reflexões sobre política e gestão educacional, de A. Cabral Neto]. Cadernos de Pesquisa, 51, e08990. https://doi.org/10.1590/198053148990

Recebido em: 06 SETEMBRO 2021 | Aprovado para publicação em: 13 OUTUBRO 2021 